\title{
Etnomatemática no contexto da formação de professores indígenas na educação superior
}

\author{
Ethnomathematics in the context of formation of \\ indigenous teachers in higher education
}

\section{Aldrin Cleyde da Cunha ${ }^{1}$ Janielle da Silva Melo da Cunha ${ }^{2}$}

\begin{abstract}
RESUMO: Este artigo analisa a Etnomatemática no contexto da formação de professores indígenas na educação superior. A metodologia utilizada foi uma revisão de literatura sobre estudos em etnomatemática e que se relacionam com a formação de professores indígenas no campo da educação matemática. Os resultados evidenciam que as práticas educativas não devem se limitar às ações didáticopedagógicas em sala de aula, mas em processos reflexivos sobre a própria prática, revelando construção das desigualdades e diferenças presentes nas instituições escolares. Neste contexto, os professores indígenas de matemática têm consciência da necessidade de uma educação diferenciada, mas ainda se encontram em um universo de indecisão em relação a sua formação. Ao mesmo tempo em que estão no meio de um conflito pessoal, entre o conhecimento escolar, dito científico, eles também almejam a construção de um novo processo de escolarização. Assim destacamos a concepção holística de educação, bem como o programa etnomatemática com sua abordagem multicultural e visão qualitativa da realidade. Na formação inicial de professores de matemática, a Etnomatemática como alternativa pedagógica pode contribuir para manutenção e dinamização das culturas indígenas a partir do desenvolvimento de estratégias de ensino que promovam o respeito, a valorização, o fortalecimento da língua materna e das raízes culturais, baseado na educação transdisciplinar e transcultural.

Palavras-chave: Educação Matemática; Formação de Professores Indígenas; Etnomatemática; Transdisciplinaridade.
\end{abstract}

ABSTRACT: This article analyzes the ethnomathematics in the context of the indigenous teachers' formation in higher education. The methodology used was a review of the literature on studies in ethnomathematics and related to the formation of indigenous teachers in the field of mathematics education. The results evidence that educational practices should not be limited to didactic-pedagogical actions in the classroom, but in reflexive processes about the practice itself, revealing the construction of the inequalities and differences present at school institutions. In this context, indigenous mathematics teachers are aware of the need for a differentiated education but are still in a universe of indecision about their education. At the same time that they are in the midst of a personal conflict, between the school knowledge, called scientific, they also aim at building a new schooling process. Thus, we highlight the holistic conception of education, as well as the ethnomathematics program with its multicultural approach and qualitative view of reality. In the mathematics teachers' initial formation, Ethnomathematics as a pedagogical alternative can contribute to the maintenance and dynamization of indigenous cultures through the development of teaching strategies that promote respect, valorization,

\footnotetext{
${ }^{1}$ Doutor em Educação Matemática pela Universidade Bandeirantes de São Paulo e professor adjunto da Universidade Federal de Grande Dourados, lotado na Faculdade Intercultural Indígena e pesquisador do Grupo Teia de Pesquisa em Educação Matemática, E-mail: aldrincunha@hotmail.com.

2 Doutoranda em Biotecnologia e Biodiversidade pela Universidade da Grande Dourados, professora assistente da Universidade Federal do Amapá, Curso de Licenciatura Intercultural Indígena, pesquisadora do Grupo de Estudos em Biotecnologia e Bioprospeç̧ão Aplicados ao Metabolismo e do Núcleo de Pesquisa História da Ciência e Ensino, E-mail: janiellecunha@hotmail.com.
} 
and reinforcement of the native language and cultural roots, based on transdisciplinary and transcultural education.

Keywords: Mathematical Education; Formation of Indigenous Teachers; Ethnomathematics; Transdisciplinarity.

\section{INTRODUÇÃO}

A origem da formação docente indígena no Brasil é no mínimo muito recente, embora, a história da educação brasileira registre a existência de escolas voltadas para as comunidades indígenas desde os primeiros contatos com os colonizadores (MELO, 2014). Ao buscar a epistemologia da formação de professores indígenas, sem dúvida, observamos que a história da educação escolar indígena no Brasil em quatro fases.

A primeira fase situa-se à época do Brasil Colônia, quando a escolarização dos índios esteve a cargo exclusivo de missionários católicos, notadamente os jesuítas. O segundo momento é marcado pela criação do SPI, em 1910, e se estende à política de ensino da Funai e a articulação com o Summer Institute of Linguistics (SIL) e outras missões religiosas. O surgimento de organizações indigenistas não governamentais e a formação do movimento indígena em fins da década de 60 e nos anos 70, período da ditadura militar, marcaram o início da terceira fase. A quarta fase vem da iniciativa dos próprios povos indígenas, a partir da década de 80 , que decidem definir e auto gerir os processos de educação formal (FERREIRA, 2001, p. 72).

Assim, na primeira fase, logo nos primeiros contatos do homem branco, que chegou ao Brasil, com as comunidades indígenas, houve um interesse de submeter os indígenas a uma doutrina escolar como forma de dominação (CUNHA, 1992). Neste período, os indígenas foram forçados a aprender uma outra língua, a língua do homem branco, e cabe aqui ressaltar que este processo não aconteceu de forma passiva e sem resistência. Muitas foram as lutas desses povos para permanecer com sua cultura. Por volta de 1549, a catequização pelos jesuítas foi mais um exemplo do interesse em doutrinar os povos indígenas na cultura do dominador (FERNANDES, 2011).

Com a criação do Serviço de Proteção ao Índio (SPI) em 1910, uma nova fase se inicia, a fase da profissionalização indígena. Mas ao contrário do que se pensa, esta profissionalização almejava "confinar os índios em espaços físicos restritos e controlados para se liberar terras para colonização; de outro, integrar dos índios à sociedade nacional, através de projetos de agricultura e de educação formal, ministrada por leigos nas escolas das reservas" (TOMMASINO, 2003).

Em 1967 foi criada a FUNAI (Fundação Nacional do Índio), para substituir o SPI, e que, assume como oficial o modelo de "educação bilíngue" proposto pelo Summer Institute of Linguístico - SIL, instalado no Brasil em 1956. Esta parceria entre a FUNAI e o SIL tinha como objetivo codificar as línguas e, a partir daí, ensiná-las nas escolas. Nesta época de regime militar, a FUNAI e o SIL elaboram normas para a Educação dos grupos 
indígenas, que, nunca foram diferentes dos de qualquer missão tradicional: a conversão dos gentios e a salvação de suas almas (SILVA; AZEVEDO, 1995, p.151).

Ainda no período de ditadura, entre os anos de 1960 e 1970, surge a formação do movimento indígena, que podemos considerar como a terceira fase da educação escolar indígena. Dessa forma, em 1973 foi criado o Estatuto do Índio, que garante a alfabetização dos índios "na língua do grupo a que pertença". E caracterizando a quarta fase, a educação escolar indígena tem fundamento nos movimentos não-governamentais que surgiram nos anos de 1980 e 1990 e que trouxeram à cena nacional os debates sobre a educação, a questão cultural e a autonomia dos povos indígenas (FERREIRA, 2001).

Um dos aspectos discutidos neste embate diz respeito a formação de professores indígenas, considerando que essa formação é fundamental à preservação dos repertórios culturais das comunidades indígenas. Até então, os indígenas quando admitidos nas escolas regulares eram obrigados a esquecer sua língua materna e sua cultura. Assim, a década de 1990, marcou um período em que foram desenvolvidos projetos sobre a educação do "índio" e sobre a formação de professores indígenas.

Dentro deste contexto, a partir de 1980, a educação brasileira estava associada às tendências progressistas, que se organizaram em correntes importantes que influenciaram o ensino enfatizando conteúdos socialmente relevantes e processos de discussão coletiva de temas e problemas de significado e importância reais. Questionava-se tanto a abordagem quanto a organização dos conteúdos, identificando-se a necessidade de um ensino que integrasse os diferentes conteúdos, com um caráter também interdisciplinar (FERREIRA, 2001). Portanto, a educação escolar em sua trajetória histórica, sempre esteve relacionada com os interesses políticos e sociais de cada época.

A partir de 1980, após muitas reivindicações das populações indígenas e de entidades não governamentais, o ideário do multiculturalismo e da interculturalidade estava consolidado no Brasil, no campo da educação e teve suas implicações nas escolas indígenas.

Para melhor compreender o desenvolvimento da educação escolar indígena no Brasil, além das políticas implementadas, faz-se necessário investigar também a legislação pois, um dos mais preciosos documentos para o estudo da evolução do caráter de uma civilização se encontra na legislação escolar, nos planos e programas de ensino e no conjunto das instituições educativas. (AZEVEDO, 1996, p. 56)

Assim, fazendo um levantamento na legislação brasileira verificamos que as políticas educacionais voltadas para a educação escolar indígena têm sua expressão na Constituição Federal (BRASIL, 1988), que passou a assegurar aos povos indígenas a formação básica comum e o respeito aos seus valores culturais e artísticos.

De acordo com a Resolução no 03/99 do CEB/CNE (BRASIL, 1999), que estabelece a estrutura e o funcionamento das escolas indígenas e define também critérios para a formação dos professores indígenas, esta deverá ser "específica" e orientada "pelas Di- 
retrizes Curriculares Nacionais". Segundo essa Resolução, "será garantida aos professores indígenas a sua formação em serviço e, quando for o caso, concomitante com a sua própria escolarização".

Pensando desta maneira, o Ministério da Educação (MEC) em 2005, criou o Programa de Apoio à Educação Superior e Licenciaturas Interculturais Indígenas - o PROLIND. O PROLIND é uma ação de apoio à formação de professores indígenas em nível superior, com formação para docência nos anos finais do Ensino Fundamental e Ensino Médio.

Essa formação ocorre de acordo com a realidade sociocultural, sociolinguística e os projetos societários dos povos envolvidos. O curso é ofertado em regime modular e duram em média quatro anos, organizado pela alternância entre Tempo-Universidade e Tempo-Comunidade. O programa visa responder pela formulação de políticas públicas de valorização da diversidade e promoção da equidade na educação, por meio de formação e capacitação de professores em nível superior.

Podemos concluir que, a epistemologia da formação de professores indígenas no Brasil, está diretamente ligada aos movimentos de lutas e resistência pela garantia da identidade cultural das comunidades indígenas. As legislações criadas até o presente momento que garantem a educação escolar indígena em seu contexto intercultural e bilíngue, bem como a formação de professores indígenas, precisam ser melhores estudadas, não sob a ótica do colonizador, mas, dentro de uma perspectiva de compromisso com esses povos, sempre esquecidos pela sociedade não mais dominante (MELO, 2014).

E assim, no aspecto educacional, as questões colocadas para a construção da escola indígena, abrem espaços e provocam reflexões sobre o nosso próprio sistema escolar, não só por constatarmos que ele é ruim e distante da nossa realidade (isso já sabemos). Mas para refletir sobre dois pontos:

1) O primeiro é compreender que a escola é um espaço de luta de classe e não apenas um campo de disputa de ideias ou um lugar de práticas políticas transformadoras;

2) O segundo ponto é entender a escola como espaço de afirmação de identidade coletiva, isto é, dos diversos grupos socioculturais que constituem a sociedade brasileira apesar de variadas práticas e políticas homogeneizadoras, e agora ditas, globalizadoras.

Neste contexto, o objetivo deste artigo é analisar a aplicação da Etnomatemática no contexto da formação de professores indígenas na educação superior, onde se considera atitudes reflexivas na pesquisa científica.

\section{METODOLOGIA}

Para este estudo com foco em Etnomatemática e Formação de Professores Indígenas na educação superior, optamos em realizar um levantamento de dados sobre o tema, com abordagem da análise qualitativa (BARROS; LEHFELD, 2002). 
Segundo Barros e Lehfeld (2002), a análise qualitativa envolve as etapas de organização, descrição e redução dos dados e interpretação destes pela categoria teórica de análise, bem como a análise de conteúdo.

Nesta perspectiva, foram relevantes pesquisas em etnomatemática, ensino de ciências, educação matemática, antropologia, educação e outras fontes de referência que selecionamos, pois constituíram a categoria teórica de análise desta investigação, além de ser suporte teórico à formação de professores indígenas na educação superior.

\section{RESULTADO E DISCUSSÃO}

A Constituição de Federal (BRASIL, 1988), assegurou aos indígenas no Brasil o direito de permanecerem indígenas, isto é, de continuarem eles mesmos, respeitando suas línguas, culturas e tradições. Ao reconhecer que os indígenas poderiam utilizar suas línguas maternas e seus processos próprios de aprendizagem na educação escolar, se espera que a escola indígena contribua com o processo de afirmação étnica e cultural desses povos, deixando de ser um dos principais veículos de assimilação e integração.

É importante ressaltar que a institucionalização dos direitos dos povos indígenas na Constituição Federal, por si só, não assegura o cumprimento destes pela sociedade majoritária dominante. Assim, é preciso planejamento de ações e acesso aos recursos financeiros com fim de proporcionar a implementação de políticas públicas que viabilizem o acesso aos direitos adquiridos por lei.

Com seus direitos previstos na Constituição Federal, surgem as leis subsequentes que tratam da educação, como a Lei de Diretrizes e Bases da Educação Nacional (BRASIL, 1996) e o Plano Nacional de Educação (BRASIL, 2001), que aborda o direito dos povos indígenas a uma educação diferenciada, pautada pelo uso das línguas indígenas, pela valorização dos conhecimentos e saberes milenares desses povos e pela formação dos próprios indígenas para atuarem como docentes em suas comunidades.

Consequentemente, a promulgação destas leis provocou a busca de uma nova ação e promoveu uma transformação nos cursos de formação de professores indígenas, isso tem gerado novas práticas a partir do desenho de uma nova função social para as escolas públicas instaladas em terras indígenas.

Logo, se atribui aos sistemas governamentais de ensino a responsabilidade legal pela educação escolar indígena. Por conseguinte, o Plano Nacional da Educação - PNE (BRASIL, 2001) assume como uma das metas a ser atingida nessa esfera de atuação, a profissionalização e o reconhecimento público do magistério indígena, com a criação da categoria de professores indígenas como carreira específica do magistério e com a implementação de programas contínuos de formação docente indígena.

Dessa forma, em suas bases legais, a formação de professores indígenas, por meio do referencial para formação de professores indígenas (BRASIL, 2002) estabelece que este professor em formação deve possibilitar diferentes relações. Já que, ao mesmo tempo ele pertence a um determinado grupo social que tem atitudes e comportamen- 
tos específicos diante do sistema público de ensino, além de ser responsável por pelos processos de aprendizagens em uma determinada turma, com fim de promover a construção de saberes.

Contudo, no que tange o contexto multilíngue em que grande parte dos processos de formação têm sido realizados. Mas é importante salientar que tem implicado resultados quase sempre preocupantes com relação ao desenvolvimento de cada uma das línguas indígenas perante as línguas nacionais.

Observa-se, de forma bastante frequente, que muitas das línguas faladas pelos povos indígenas na sua sociedade durante os cursos ocupam um lugar marginal e eventual no currículo. São pouco contempladas como objeto de estudo e também pouco utilizadas como língua veicular nas situações de comunicação oral e escrita. Raramente são faladas na comunicação formal entre professores indígenas e entre estes e seus formadores, estando muitas vezes restrita à comunicação informal entre professores indígenas quando falantes da mesma língua.

As virtudes do bilinguismo promovem uma ética entre conjuntos de fricção (a língua um e a dois), conjuntos incompletos, bem entendido, que se movem instalados por uma espécie de completude incompleta oi pela tradução entre dois conjuntos, abrindo a possibilidade de uma terceira via, de um terceiro rosto, de que ambos os conjuntos saem iluminados. Babel invertida, com fios de ouro, com uma etimologia que olha escandalosamente para o futuro. (LUCCHESI, 2015, p. 283).

Porém, podemos notar que o uso da língua materna está presente em todo momento no cotidiano dos futuros professores indígenas, seja na aldeia, na escola em que leciona e em outros espaços de seu convívio em que estabelece suas relações sociais, políticas, econômicas e culturais. Por isso, é importante pensar a formação que garanta o uso das diversas formas de manifestações e dos diversos elementos culturais que constitui a identidade de um grupo étnico.

Atualmente, o Ministério da Educação (MEC) conta com a Secretaria de Educação Continuada, Alfabetização, Diversidade e Inclusão (SECADI). Esta atua em articulação com os sistemas de ensino na implementação de políticas educacionais nas áreas de alfabetização e educação de jovens e adultos, educação ambiental, educação em direitos humanos, educação especial, do campo, escolar indígena, quilombola e educação para as relações étnico-raciais, dados estes que estão disponíveis no site do referido ministério (MINISTÉRIO DA EDUCAÇÃO, 2017).

O objetivo da SECADI é contribuir para o desenvolvimento inclusivo dos sistemas de ensino, voltado à valorização das diferenças e da diversidade, à promoção da educação inclusiva, dos direitos humanos e da sustentabilidade socioambiental, visando à efetivação de políticas públicas transversais e intersetoriais. (MINISTÉRIO DA EDUCAÇÃO, 2017). 
Uma das ações importantes da SECADI, foi a implementação do Programa de Apoio à Formação Superior e Licenciaturas Interculturais Indígenas (PROLIND), cuja finalidade é apoiar projetos de cursos de licenciaturas específicas para a formação de professores indígenas, isto é, para o exercício da docência nas escolas indígenas, buscando integrar ensino, pesquisa e extensão, além de promover a valorização do estudo em temas como línguas maternas, gestão e sustentabilidade das terras e culturas dos povos indígenas.

A implementação da formação professor indígena visa oportunizar o desenvolvimento de formas de cooperação e práticas de reciprocidade uns com os outros e evitar as práticas que enaltecem o indivíduo em detrimento do coletivo, procurando fortalecer nos professores indígenas o compromisso com sua comunidade, história de seu povo e práticas tradicionais, sem que haja uma folclorização de sua cultura.

Em outras palavras, evitando assim, que na formação inicial, esses professores possam se iludir com a ciência do outro e pelos seus critérios de validação de conhecimento, desenvolvendo, no processo de ensino e de aprendizagem nas escolas indígenas, atitudes que os façam desconsiderar a sua própria ciência, renunciando as suas raízes culturais, tendo como premissa a valorização apenas do conhecimento ocidental como único, universal e verdadeiro.

[...] O principal ingrediente da tomada de decisão do professor à direção das aulas e do aprendizado do aluno é o descobrimento, pelo professor, do conhecimento do aluno. $\mathrm{O}$ aluno chega ao processo educacional com uma riqueza de experiências. $O$ ensino de matemática não mais se fundamenta na estrutura de disciplinas, mas ao invés, se estrutura no conhecimento do aluno. Para tanto o professor necessita organizar o trabalho na sala de aula de maneira a eliciar o conhecimento do aluno para que este conhecimento possa ser analisado. Também é importante criar atividades que levem o aluno a buscar suas experiências, conhecimentos já formados" (D'AMBROSIO, 1990, apud DOMITE 2002, p.424).

Ao pensarmos nas possibilidades da Etnomatemática na formação inicial de professores indígenas de matemática, temos que almejar uma educação transdisciplinar e transcultural.

D’Ambrosio (2011) provoca esta discussão, quando destaca que:

[..] o que aprendemos da história é que a busca de sobreviver se complementa com a busca de transcender o existencial (passado e futuro) e o factível (explicável e inexplicável). A busca de compreensão do mundo na sua integralidade exige que as dimensões de sobrevivência e de transcendência se complementem (D'AMBROSIO, 2011, p. 13).

Portanto, na formação de professores indígenas há necessidade de uma visão abrangente de ensino e de aprendizagem da Etnomatemática ocidental e da Etnomatemática indígenas para que se desenvolvam estratégias que aprimorem a relação entre 
as duas ciências.

Sendo assim, é preciso promover aos futuros professores indígenas de matemática, ferramentas metodológicas e fundamentos teóricos, baseados em pesquisas em etnomatemática, para que eles possam selecionar material no seu ambiente (tangíveis) e conhecimento ancestral (intangível) e que podem ser incorporados na formulação de um currículo para promover o desenvolvimento de conteúdo intercultural, considerando as duas visões de conhecimentos: ocidentais e indígenas (LUPIÁÑEZ, 2009).

Em se tratando da educação atual, em particular, a formação de professores indígenas verificamos que a organização dos diversos corpus de conhecimento repousam nas disciplinas, caracterizadas pelo desenvolvimento de métodos específicos para conhecer objetos de estudo bem definidos.

Assim, recorremos ao pensamento D'Ambrosiano, no que se refere a sua interpretação sobre o conhecimento disciplinar:

[...] Entendemos também que o conhecimento disciplinar se mostra insuficiente para lidar com os complexos fenômenos da realidade e pratica-se em um modelo multidisciplinar, no qual se procura reunir resultados obtidos mediante o enfoque disciplinar para lidar com situações mais complexas. Igualmente, o enfoque multidisciplinar é incapaz de explicar e de lidar com o crescente reconhecimento da complexidade dos fenômenos naturais e sociais (D'AMBROSIO, 2011, p. 9).

Então, poderíamos pensar a formação de professores indígenas de matemática como uma prática interdisciplinar, misturando as diversas disciplinas em seus variados e possíveis resultados, buscando um foco na vida social e cotidiana.

Nessa perspectiva, muitas reflexões surgem, como:

[...] Mas, será que há limites para o conhecimento? Haverá a possibilidade de um sistema total de conhecimento ou, como costumam dizer os físicos, de uma teoria de tudo? Assim, mesmo tendo essa perspectiva, mesmo considerando as práticas interdisciplinares, que hoje, com raras exceções, estão presentes na pesquisa científica, e que procura explicações finais, ainda assim, não conseguiríamos superar a angústia da ameaça de extinção que pesa sobre a humanidade. Então, devemos levar em conta outras possibilidades além da interdisciplinaridade e não podemos excluir a possibilidade de existirem outros sistemas de conhecimento nos quais a fragmentação do saber não tenha sido tão rígida quanto o que vemos no sistema de conhecimento ocidental" (D'AMBROSIO, 2011, p. 9).

Esses sistemas de conhecimento, em algumas sociedades, são aprimorados. Já em outras são desfigurados pela exposição com a civilização ocidental, bem como é possível que esses sistemas poderão contribuir para a superação do impasse existencial do ser humano, pois mantêm a sua essência fundamentada em suas tradições.

Por exemplo, os sistemas de conhecimentos indígenas, que são pautados na ex- 
periência de vida, de mundo, das pessoas, no viver o tempo, na manutenção de seus valores culturais, na espiritualidade, nos ritos, nas crenças e no saber fazer, e tudo está relacionado de maneira holística e sem a fragmentação do conhecimento, funcionado em uma verdadeira simbiose entre homem e natureza. Desenvolvendo a sua ciência e suas tradições, promovendo o seu modo de vida, sua própria cosmologia (CUNHA, 2016).

Outros sistemas (de indígenas, de trabalhadores rurais, de operários, entre outros) culturais desenvolvem técnicas, habilidades e práticas para lidar com a realidade, de manejar os fenômenos naturais, e mesmo de teorizar essas técnicas, habilidades e práticas de maneiras distintas, embora os meios de fazer isso encontrem uma universidade decrescentemente hierarquizada de processos de contagem, medições, ordenações, classificações e inferências. São exemplos deste fato os grupos culturalmente diferenciados, como grupos de adolescentes de uma comunidade indígena e jovens profissionais de uma cidade industrializada que podem explicar o fenômeno da chuva de maneira absolutamente distinto, inclusive quantificando-o de outro modo (D'AMBROSIO, 1998).

De fato, o principal desafio na formação de professores indígena reside em conseguir manter as especificidades culturais de cada etnia e, ao mesmo tempo, ensinar um conjunto de saberes que é parte do patrimônio da sociedade mais abrangente. Isso constitui o desafio de recriar a cultura tradicional indígena em um ambiente novo de escolarização (FUNARI e PIÑON, 2014).

Logo, há de se considerar que:

[...] Do encontro das ciências e das tradições culturais resultam transformações profundas dos sistemas de explicações. Essas transformações têm sido notadas no desenvolvimento científico e tecnológico, nos sistemas de comunicação e de transporte, nos meios de produção e no próprio conceito de propriedade. Um questionamento frequente se refere à universalidade dessas transformações. E temos verificado que há indicadores de que esse encontro é efetivamente um movimento planetário, prenúncio de uma civilização planetária, produto de um processo dinâmico e multicultural" (D'AMBROSIO, 2011, p. 10).

Nesse sentido, a Etnomatemática insere-se no contexto da formação de professores indígenas, privilegiando atitudes investigativas, reflexivas, tendo um caráter permanente e coletivo, pois as práticas educativas não devem se limitar às ações didáticopedagógico em sala de aula. Mas em processos reflexivos sobre a própria prática, como também, buscar reflexões teóricas que permitam à equipe pedagógica desvendar os processos de construção das desigualdades e diferenças presentes no interior das instituições escolares (OREY e DOMITE, 2004).

Assim, de acordo com D’Ambrosio (2007), a presença da Etnomatemática na formação de professores poderá promover a matemática humanística, que é vista como uma disciplina para preservar a diversidade e eliminar desigualdade discriminatória entre os diferentes tipos de conhecimento. Além disso, as visões multidisciplinares ou in- 
terdisciplinares são úteis e importantes, já que permitem reconhecer uma visão completa da realidade, quando o conhecimento é subordinado a uma visão transdisciplinar.

A partir do modelo de matemática humanista, podemos interpretar quase todas as abordagens modernas de conhecimento, pois o conhecimento é o resultado de um longo processo cumulativo, em que as fases são identificadas, não naturalmente dicotômica umas às outras. É quando ocorre a geração, organização intelectual, organização social ou difusão em um processo cíclico de aquisição individual e social de conhecimento, submetido às condições específicas de estímulos e subordinação ao contexto natural, cultural e social (D’AMBROSIO, 2002; 2007),

É importante esclarecer, que entendemos o conhecimento, conforme perspectiva D’Ambrosiana:

[...] O conhecimento é então encarado como modos, estilos, técnicas de explicar, de conhecer, de lidar com a realidade como ela se manifesta em distintos ambientes naturais e culturais. Obviamente, esses modos, estilos e técnicas não se realizam no modelo disciplinar, nem mesmo nas suas variantes da multidisciplinaridade e da interdisciplinaridade. Exigem uma visão transdisciplinar do conhecimento (D'AMBROSIO,2001, p. 10).

Etimologicamente, "trans" é o que está ao mesmo tempo entre as disciplinas, através das diferentes disciplinas e além de todas as disciplinas, remetendo também à ideia de transcendência. A transdisciplinaridade como uma teoria do conhecimento é uma compreensão de processos, como ainda o diálogo entre as diferentes áreas do saber e uma aventura do espírito, bem como é uma nova atitude, é a assimilação de uma cultura, é uma arte, no sentido da capacidade de articular a multirreferencialidade e a multidimensionalidade do ser humano e do mundo (COLL, 2002).

Deste modo, a formação de professores indígenas de matemática pode ser compreendida como um processo dinâmico e transdisciplinar e leva o indivíduo a:

[...] a tomar consciência da essencialidade do outro e da sua inserção na realidade social, natural e planetária, e cósmica. Uma consequência imediata da essencialidade é que a inserção só pode se dar por um relacionamento de respeito, solidariedade e cooperação com o outro, consequentemente com a sociedade, com a natureza e com o planeta, todos e tudo integrados na realidade cósmica. Esse é o despertar da consciência na aquisição do conhecimento. A grande transformação pela qual passa a humanidade é o encontro do conhecimento e da consciência (D'AMBROSIO, 2015, p. 3).

Isso implica que a formação promova uma postura sensível, intelectual e transcendental perante si mesmo e perante o mundo. Isto é, implica, também, que possibilite aprender a decodificar as informações provenientes dos diferentes níveis que compõem o ser humano e como elas repercutem uns nos outros. Em outras palavras, transformando nosso olhar sobre o individual, o cultural e o social, remetendo à reflexão respei- 
tosa e aberta com relação às culturas do presente e do passado, buscando contribuir com a sustentabilidade do ser humano e da sociedade.

D’Ambrosio (2001) salienta o que é fundamental na formação transdisciplinar:

[...] O essencial em uma formação transdisciplinar reside numa postura de reconhecimento que não há espaço e tempo culturais privilegiados que permitam julgar e hierarquizar, como mais correto ou mais certo ou mais verdadeiro, complexos de explicação e convivência com a realidade que nos cerca. Ela repousa sobre uma atitude aberta, de respeito mútuo e mesmo humildade, com relação a mitos, religiões e sistemas de explicações e conhecimentos, rejeitando qualquer tipo de arrogância e prepotência. Por exemplo, a valorização da cultura oral em uma escola tradicionalmente dominada pela escrita também permite maior abertura a algumas culturas que valorizam essa forma de comunicação, é o que acorre na maioria das comunidades indígenas" (D'AMBROSIO, 2001, p. 5).

Por isso, a transdisciplinaridade é, na sua essência, transcultural. E, por conseguinte, exige a participação de todos, vindo de todas as regiões do planeta, de diferentes tradições culturais e com as mais diversas formações e experiências profissionais.

Portanto, é legítimo indagar de que maneira a formação de professores indígenas de matemática, considera e valoriza a cultura dos acadêmicos. Faz-se necessário mudar as representações, concepções de diferenças culturais como sendo um problema (déficit, perturbação e transição), bem como considerar a diferença cultural como uma grande oportunidade (de troca, experiência, recurso e enriquecimento).

A formação de professores indígenas exige um contato mais amplo e efetivo com a prática transdisciplinar, com as questões sociais e culturais que envolvem os processos educativos. Além da formação técnica, é preciso que o futuro professor desenvolva aspectos como a sensibilidade, senso de solidariedade, cooperação, respeito e compromisso com a sua comunidade.

De acordo com Meirieu (1991), a exigência ética do educador se efetiva quando este consegue relacionar dois princípios aparentemente contraditórios. De um lado, o princípio da educabilidade, que representa a expectativa de que o outro adquira seus aprendizados escolares e do outro lado, o princípio da liberdade, que postula que nada pode ser feito sem o apoio do outro, do educando, isto é, sem considerar a cultura como um recurso para aprendizagem.

É necessário que os educadores considerem que todas as suas ações em classe se constituem em um comportamento cultural. Ao se considerar a cultura, estamos sensíveis às diferentes situações criativas que envolvem os estudantes pertencentes a um contexto cultural distinto.

No que se refere a proposta transdisciplinar, D’Ambrosio (2001) explica: 
[...] A essência da proposta transdisciplinar parte de um reconhecimento que a atual proliferação das disciplinas e especialidades acadêmicas e não acadêmicas, conduz a um crescimento incontestável do poder associado a detentores desses conhecimentos fragmentados, podendo assim agravar a crescente iniquidade entre indivíduos, comunidades, nações e países. Além disso, o conhecimento fragmentado dificilmente poderá dar a seus detentores a capacidade de reconhecer e enfrentar os problemas e situações novas que emergem de um mundo, cuja complexidade natural acrescenta-se a complexidade resultante desse próprio conhecimento, transformado em ação, que incorpora novos fatos à realidade, por meio das tecnologias" (D'AMBROSIO, 2001, p. 9).

Precisamos então, adotar uma postura transdisciplinar na formação de professores indígenas de matemática, promovendo um relacionamento de respeito, solidariedade e cooperação com o outro, para superar a ideia de omnipotente e de omnisciente do ser humano, considerando a diversidade cultural o caminho para o desenvolvimento da espécie humana.

Dessa forma, na busca de incorporar a Etnomatemática na formação de professores indígenas de matemática, partiremos das reflexões de D’Ambrosio (1993) sobre quais deverão ser as características desejadas em um professor de matemática no século XXI, e a partir dessas características estabeleceremos uma relação com o contexto da formação de professores indígenas.

Ela considera que o professor de matemática deverá ter: a visão do que vem ser a matemática ou, no nosso caso, a Etnomatemática; a visão do que constitui a atividade Etnomatemática; a visão do que constitui a aprendizagem da Etnomatemática; e a visão do que constitui um ambiente propício à aprendizagem da Etnomatemática (D’AMBROSIO, 1993). Indagamos então, o que vem a ser ou, como acontece nas práticas o saber fazer e, como está relacionada ao ambiente cultural a Etnomatemática?

$\mathrm{Na}$ formação de professores indígenas de matemática, procuramos entender o que constitui as atividades, a aprendizagem e o ambiente propício à aprendizagem da Etnomatemática no contexto da escola indígena, isto é, levando o acadêmico a compreender que a sua formação constitui um momento de reafirmação e revitalização de sua identidade cultural.

Momento em que se tem um espaço de articulação e de troca de informações e, que possibilita a relação com outros grupos socioculturais, além de um espaço de pesquisa de suas necessidades cotidianas, de métodos específicos ao seu contexto e de suas raízes culturais. Logo, é essencial desenvolver na formação de professores indígenas, situações-problema que articulem as experiências anteriores, dos saberes, dos fazeres, dos valores, das crenças e da cultura dos educandos, com suas novas perspectivas, esperanças, aspirações, planos e possibilidades para o futuro.

O importante é envolver oportunidades reais e também vistas nas perspectivas dos educandos, o que faz com que se tornem sujeitos ativos no processo de ensino e aprendizagem, fazendo-se necessário mudar nossa interpretação sobre as atividades didáticas desenvolvidas na formação de professores, de maneira, que não apenas tra- 
tem da interpretação cognitiva, mas também sociopolítica.

É indispensável oportunizar ao educando, entender que a formação de professores é um processo contínuo de reflexão sobre a ação, mas sem deixar de considerar a sua experiência pessoal, os seus saberes práticos e teóricos, valores, o seu modo de interpretar a realidade, tudo em um processo coletivo, proporcionando o diálogo e o debate do grupo em formação.

No que se refere a uma formação de professores pela via da Etnomatemática, é preciso que tal formação não considere apenas o conhecimento cultural do educando e formas que fornecem uma discussão e legitimação da mesma pelos educandos, mas também considere a atualização científica e pedagógica geral da matemática que está presente no contexto escolar, de modo a contestá-la ou incorporá-la na medida da situação-problema em questão.

O grande objetivo da Etnomatemática é atingir a paz e viver, com dignidade, num futuro que é desconhecido e, especificamente, na formação de professores indígenas de matemática, a missão é plantar e difundir as dimensões morais, política e humanitária no comportamento profissional.

Estamos passando por um processo de transição, na qual se destacam várias áreas de conhecimento, como tecnociência, informática e inteligência artificial, biotecnologia e ciências da mente, internet e globalização, que promovem novas visões do cosmos, da natureza, da sociedade e do homem.

As consequências desse processo é o surgimento de novas urgências, como de uma ética tecnológica, ética científica e ética matemática e, portanto, de um outro perfil de professores de matemática. Isso depende de uma nova formação, particularmente nas licenciaturas interculturais, deve se ter uma menor ênfase na matemática e nas teorias de aprendizagens convencionais e maior ênfase em sociologia e antropologia, em história, na nova matemática e nas ciências atuais, incluindo as novas ciências da mente e da cognição e um novo conceito de aprendizagem, com uso das tecnologias existentes (D’AMBROSIO, 2005).

Isso nos remete à importância de se refletir sobre a matemática a sua inserção social, na história da matemática, o seu estado atual e no futuro da matemática, ou seja, pensar o saber e o fazer etnomatemático, bem como a desmistificação da matemática e das ciências em geral.

A este respeito, D’Ambrosio (1989) reflete que:

[...] um dos maiores desafios que os matemáticos têm pela frente é tornar coisas difíceis acessíveis ao maior número possível de indivíduos. Conhecimento é o mais forte instrumento de poder. Não é possível que o conhecimento atual e que realmente serve na condução da sociedade fique restrito a poucos. É a isso que eu chamo a desmistificação da matemática e das ciências em geral (D’AMBROSIO, 1989, p. 512).

Todos esses movimentos de inovação, relacionados com a problemática central 
das relações entre a matemática e a sociedade, só se tornam efetivamente possíveis quando estiver devidamente incorporado aos currículos. Isto é, não se trata de organizar currículos para ensinar ao estudante e depois cobrá-los na aplicação de testes e exames, o que ele conseguiu reter daquele conteúdo.

A educação é algo mais que o ensino de conteúdos de um currículo escolar. É na escola que o indivíduo será motivado e sensibilizado para observar criticamente tudo, para socializar seu conhecimento e seu comportamento, ajustando-os ao seu grupo.

[...] Talvez o que interesse mais diretamente ao professor seja a pergunta "e ao entrar numa classe de 10 grau (ou 20 ou 3 ) como posso ensinar Etnomatemática?". Simplificando a resposta, diríamos Etnomatemática não se ensina, se vive e se faz". Em outros termos, o professor deverá mergulhar no universo sociocultural de seus alunos, compartilhando com eles de uma percepção da realidade que lhe é, ao professor, muitas vezes difícil de acompanhar. E a pergunta inicial do professor passaria a ser reformulada assim "e ao entrar numa clas-

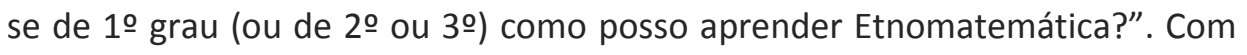
essa atitude, ele está se iniciando num processo que lhe abrirá uma nova dimensão como profissional e como ser humano" (D'AMBROSIO,1988, p. 3).

Dessa forma, inspirados em D’Ambrosio (2005), propomos que a formação de professores indígenas de matemática, seja, organizada e trabalhada em três momentos simultâneos:

- Momentos de sensibilização: um apanhado da história da humanidade, discutindo o fenômeno vida e a história da presença humana, buscando uma relação com a história de vida da comunidade indígena;

- Momentos de instrumentalização: fornecimento dos instrumentos comunicativos, analíticos e materiais/tecnológicos, valorizando o contexto sociocultural;

- Projetos: dando amplo espaço para cada estudante exercer sua criatividade, mediante projetos ou atividades que os motivem, individualmente ou em grupo, no decorrer da sua formação, fortalecendo suas raízes culturais.

Nessa perspectiva, a Etnomatemática reivindica transformações que superam os aspectos metodológicos, direcionando nosso olhar para as questões socioculturais que exigem uma pedagogia da inclusão de espaços para a diversidade e para os saberes presentes em diferentes contextos.

Deste modo, ao tratar da formação de professores indígenas, é necessário refletir acerca do papel da cultura. O estudo de Silva (1993) contribui com esta discussão, já que interpreta que:

[...] o papel da cultura é o de codificar o mundo, ou melhor dizendo, a cultura contém a trama de signos com que as pessoas significam os objetos, os acontecimentos, as situações e as outras pessoas que as rodeiam. Cada indivíduo, de posse do código, se movimenta facilmente no universo de sua cultura, age na certeza de ter seu comportamento confirmado pelo grupo (SILVA,1993, p. 28). 
Por conseguinte, é importante entender a Etnomatemática em todas as suas dimensões, uma vez que possibilita uma práxis transformadora, pois:

[...] a sua essência consiste na mutação de um paradigma universalista para um paradigma ético e solidário, ou seja, propondo uma mutação da dimensão individualista e competitiva para uma dimensão social e solidária, e isso pode ser um fator determinante para a recuperação da autoestima dos grupos marginalizados, na busca de uma sociedade mais inclusiva (MONTEIRO et al., 2004, p. 24).

Ao considerar as possibilidades das práticas Etnomatemáticas provocarem transformações políticas e sociais aos grupos marginalizados, precisamos entender o lugar da diversidade cultural no contexto da formação de professores indígenas, o que pode ser identificado e verificado nas várias dimensões da Etnomatemática, as quais trataremos a seguir a partir dos trabalhos de D’Ambrosio (2007; 2009).

- Dimensão conceitual:

Está relacionada ao conhecimento e comportamento, que são gerados a partir das diferentes representações da realidade que, por sua vez, respondem às percepções de tempo e espaço. A Etnomatemática é concebida como uma forma de expressar o conhecimento para resolver problemas existenciais relacionadas com a sobrevivência e transcendência. Essa dimensão pode ser facilmente percebida no jeito de ser das comunidades indígenas, na forma de ver, lidar e se relacionar com a natureza, com o mundo, na sua cosmologia.

- Dimensão histórica:

Esta dimensão aborda as condições históricas em que ocorre o desenvolvimento e aplicação do conhecimento matemático, prevalecendo o conhecimento do sistema ocidental da Etnomatemática, embora, de acordo com D’Ambrosio (2007), não haja indicação de que este é um sistema permanente e universal, desde que as pesquisas sejam um ponto de transições entre a análise qualitativa e quantitativa dos fatos e fenômenos.

Ao pensarmos na história da humanidade e dos grupos socioculturais constituídos ao longo do tempo, chegaremos às comunidades indígenas, e que ao longo de sua luta pela sobrevivência e transcendência desenvolveram, à sua forma de organização, uma maneira própria de matematizar o mundo.

- Dimensão cognitiva:

É uma característica da espécie humana e que se mostra explicitamente como práticas matemáticas. D’Ambrosio $(2007,2009)$ argumenta que a espécie humana utiliza as suas memórias e soluções de situações-problemas que ocorreram, ao longo de sua história, isso, quando confrontados com novas situações-problemas, ou seja, a sobrevivência e a transcendência são a essência do ser (verbo) humano; o ser (substantivo) humano como espécie, luta pela sobrevivência e o planejamento do processo de sobrevivência, demonstra a transcendência da espécie humana, pois, reúne as experiências 
de situações anteriores, adaptando estas a novas situações e, pelas quais, se incorporam a memória, novos fatos e conhecimentos.

Embora o conhecimento seja gerado individualmente, a alteridade promovida pela comunicação, faz com que esse conhecimento seja enriquecido pelas informações percebidas pelos outros. Nas culturas indígenas em geral, percebemos os conhecimentos ancestrais e que estes são transmitidos de geração em geração, apesar do encontro com outras culturas, seus valores, suas crenças, a sua espiritualidade, sua cultura sobrevive ao tempo, com adaptações, como resistência, sobrevivência e transcendência, as adversidades do mundo moderno.

- Dimensão epistemológica:

Nesta dimensão, a abordagem de D'Ambrosio (2009) usa a justificativa da consciência como uma força motriz por trás do processo de sobrevivência e transcendência na espécie humana, já que o processo de aquisição de conhecimento (sensorial, intuitiva, emocional ou racional) é ação governada por uma dialética entre saber e fazer, que é motivada pela consciência e os reflexos gerados durante o processo cognitivo.

Quando adentramos no universo de um determinado grupo étnico indígena, compreendemos onde se encontra a essência do ser indígena, do seu modo de agir, das suas crenças, dos seus cantos, das suas rezas, dos seus ritos, do seu modo de viver, e essa maneira de ser, que se manifesta no presente, que vem do passado e que se projeta ao futuro, são guiadas por um sentimento maior entre o ser humano e a natureza, entre o mundo real e o espiritual, e que tem sua origem na sua cosmologia, na sua cosmovisão.

- Dimensão política:

Nessa dimensão, D’Ambrosio (2009) argumenta que a matemática tem desempenhado um papel de poder e segregação, e deveria contribuir para descolonização e para oportunidades de acesso para os subordinados, marginalizados e grupos excluídos. Em um grupo sociocultural, que vive uma constante disputa por territórios, pela sobrevivência do próprio grupo étnico, que luta pela preservação do seu ambiente cultural, pela vida, é necessário ter possibilidades e oportunidade para a garantia de sua existência.

- Dimensão educacional:

D’Ambrosio (2009) afirma que a Etnomatemática visa melhorar a matemática acadêmica pela incorporação de valores, como o respeito, a solidariedade e a cooperação, e isso será possível pela incorporação da matemática a um contexto cultural e educação matemática contextualizada.

Essa proposta aponta uma concepção holística de educação e etnomatemática, já que sua abordagem multicultural e visão qualitativa da realidade busca levar a esta concepção. Um dos caminhos para as comunidades indígenas, em busca do respeito, da valorização, do fortalecimento da sua língua, da sua cultura é o acesso à educação escolar, ou seja, uma educação transdisciplinar e transcultural. 


\section{CONSIDERAÇÕES FINAIS}

No Brasil, a formação de professores indígenas já ocorre em várias instituições de ensino superior, com cursos voltados para atender suas especificidades como parte dos projetos financiados pelo PROLIND, mas sua oferta ainda deixa a desejar no que se refere ampliação de projetos e ações.

Como exemplos, podemos citar: a dificuldade de financiamentos por parte dos órgãos responsáveis, a falta da aceitação (total e real) por parte das instituições de ensino superior a um modelo diferenciado na oferta dos cursos de licenciaturas interculturais e quadro docente insuficiente, e de certa forma, despreparado para atuar na educação superior indígena, o que se justifica por terem passado por uma formação que leva o corpo docente a enfrentar dificuldades em mudar sua prática docente disciplinar, que reproduz o modelo de sua formação acadêmica, quando o que se espera é a prática docente transdisciplinar.

Neste contexto, as pesquisas em etnomatemática contribuem com a formação de professores indígenas na educação superior, desenvolvendo a geração, organização e difusão do conhecimento, na promoção do respeito, da valorização, do fortalecimento da sua língua e de sua cultura, pois, em seus fundamentos temos uma educação transdisciplinar e transcultural. Assim, o Programa Etnomatemática colabora com a comunidade indígena na busca e ocupação de seu lugar de direito no ensino superior, considerando o seu pertencimento a um grupo étnico e sua comunidade local.

\section{REFERÊNCIAS}

BARROS, A. D. J. P. D.; LEHFELD, N. A. D. S. Projeto de Pesquisa: propostas metodológicas. $13^{\mathrm{a}}$ ed. Petrópolis: Vozes, 2002.

BRASIL. Estatuto do Índio, 1973. Disponível em: http://www.planalto.gov.br/cci vil 03/leis/16001.htm, Acesso: 10 de julho de 2017.

. Constituição Federal. Brasília: Gráfica do Senado, 1988. Disponível em: http:// www.planalto.gov.br/ccivil 03/Constituicao/Constituicao.htm, Acesso: 18 de junho de 2017.

. Decreto 5.051, de 19 de abril de 2004. Promulga a Convenção n. 169 da Organização Internacional do Trabalho - OIT sobre Povos Indígenas e Tribais. Disponível em: http://portal.mec.gov.br/sesu/arquivos/pdf/decreto5051.pdf, Acesso: 10 de julho de 2017.

. Lei 10.172/2001. Plano Nacional de Educação. Disponível em: http://www.pla nalto.gov.br/ccivil 03/leis/leis 2001//10172.htm, Acesso: 23 abril 2016.

. Lei 11.153, de 29 de julho de 2005. Dispõe sobre a instituição da Fundação Universidade Federal da Grande Dourados - UFGD, por desmembramento da Funda- 
ção Universidade Federal de Mato Grosso do Sul. Disponível em: http://www.planal to.gov.br/ccivil 03/ Ato2004-2006/2005/Lei/L11153.htm, Acesso: 10 de julho de 2017.

. Lei 9394 de 20 de dezembro de 1996. Estabelece as Diretrizes e Bases da Educação Nacional, Disponível em: http://www.planalto.gov.br/ccivil 03/Leis/L9394. htm, Acesso: 18 de junho de 2017.

. Resolução CEB/CNE $n^{\circ} 3$ de 10/11/1999. Fixa as Diretrizes Nacionais para o funcionamento das escolas indígenas. Diário Oficial da União, 14 de dezembro de 1999.

- Programa de Apoio à Formação Superior e Licenciaturas Interculturais Indígenas (PROLIND). O Edital de Convocação n. 05 de 29 de junho de 2005. Diário Oficial da União, Seção 3, p. 49. 1998.

. Referencial Curricular Nacional para as Escolas Indígenas. Brasília: MEC/SEF,

. Referencial para Formação de Professores Indígenas. Brasília: MEC, 2002.

COLL, A. N. As Culturas não são Disciplinas: Existe o Transcultural? In. CETRANS. (Coord.). Educação e Transdisciplinaridade II. São Paulo: Triom/Unesco, 2002. p. 73-92.

CUNHA, A. C. Contribuição da etnomatemática para a manutenção e dinamização da cultura Guarani e Kaiowá na formação inicial de professores indígenas. (Tese de Doutorado). Universidade Anhanguera de São Paulo. São Paulo, 2016.

CUNHA, M. C. Legislação Indígena no século XIX. Comissão Pró- índio de São Paulo: Edusp, 1992.

D'AMBROSIO, U. Educação matemática: Da teoria à prática. $17^{a}$ ed. Campinas: Papirus, 2009.

A transdisciplinaridade como uma resposta à sustentabilidade. Terceiro Incluído, Goiânia, v. 1, n.1, Jan./Jun, 2011.

- Do Misticismo à Mistificação. In: D’AMBRosıO, U. (Org.) Anais do Congresso Latino Americano de História da Ciência e da Tecnologia. São Paulo: Nova Stella, 1989, p. 505-514.

. Etnomatemática se ensina?, Boletim de Educação Matemática, Rio Claro, v. 3, n. 4, 1988, p. 1-3.

. Etnomatemática. São Paulo: Editora Ática, 1990.

. Etnomatemática: Arte ou técnica de explicar ou conhecer. $5^{\text {a }}$ ed. São Paulo: Ática, 1998. (Série Fundamentos).

. La matemática como ciencia de la sociedad. In: GIMÉNEZ, J.; DIÉZ-PALOMAR, F. J.; CIVIL, M. (Coord.). Educación Matemática y Exclusión. Barcelona: Graó, 2007, p. 
83-102.

. Sociedade, cultura, matemática e seu ensino. Educação e Pesquisa, São Paulo, v. 31, n. 1, p. 99-120, Jan./Abr. 2005.

- Transdisciplinaridade e a proposta de uma nova universidade, 2005. Disponível em: https://sites.google.com/site/etnomath/41, Acesso: 18 de junho de 2017.

. Transdisciplinaridade. São Paulo: Palas Athena, 2001.

D’AMBROSIO, B. S. Formação de professores de Matemática para o século XXI: o grande desafio. Pró-Posições, Campinas, v. 4, n. I [10], 1993, p. 35-41.

DOMITE, M. C. S. Da compreensão sobre formação de professores e professoras numa perspectiva etnomatemática. In: KNIJNIK, G.; WANDERER, F.; OLIVEIRA, C. J. (Org.). Etnomatemática, Currículo e Formação de Professores. Santa Cruz do Sul: Ed UNISC, 2002, p. 419-431.

FERREIRA, M. K. A educação escolar indígena: um diagnóstico crítico da situação no Brasil. In SILVA, A. L. S.; FERREIRA, M. K. (Org.). Antropologia, História e Educação: a questão indígena e a escola. São Paulo: FAPESP/GLOBAL/MARI, 2001.

FUNARI, P. P; PIÑON, A. A temática indígena na escola: subsídios para os professores. São Paulo: Contexto, 2014.

LUCCHESI, M. Direitos Linguísticos. In: BAPTISTA, A. M. H.; HUMMES, J. M.; DAL BELLO, M. P.; D’AMBROSIO, U. Tempo-Memória na Educação: Reflexões. São Paulo: BT Acadêmica, 2015.

LUPIAÑEZ, J. Expectativas de aprendizaje y Planificación curricular en um Programa de formación inicial de Profesores de matemáticas de secundaria. (Tesis Doctoral). Universidad de Granada. España, 2009.

MATO GROSSO DO SUL. Deliberação CEE/MS n 4324, de 03 de agosto de 1995, aprovou o documento Diretrizes Gerais/Educação Escolar Indígena, elaborado pela Secretaria de Estado de Educação/MS/92.

MEIRIEU, P. Le choix d'eduquer, éthique et pédagogie. Paris: ESF,1991.

MELO, J. S. C. Formação de Professores Indígenas: Estratégias para o ensino de ciências e biologia. (Dissertação de Mestrado). Fundação Universidade Federal de Mato Grosso do Sul. Campo Grande, 2014.

MINISTÉRIO DA EDUCAÇÃO. Secretaria de Educação Continuada, Alfabetização, Diversidade e Inclusão (SECADI). Disponível em: http://portal.mec.gov.br/secretaria-de-edu cacao-continuada-alfabetizacao-diversidade-e-inclusao/apresentacao, Acesso: 18 de junho de 2017.

MONTEIRO, A.; OREY, D.; DOMITE, M. C. S. Etnomatemática: papel, valor e significado. In. RIBEIRO, J. P. M.; DOMITE, M. C. S.; FERREIRA, R. (Org.). Etnomatemática: papel 
valor e significado. São Paulo: Zouk, 2004, p. 13-37.

PIOVEZANA, L. A educação no contexto indígena kaingang. In. NACKE, A.; RENK, A.; PIOVESANA, L.; e BLOEMER, N. M. S. (Ed.). Os Kaingang no Oeste Catarinense: tradição e atualidade. Chapecó: Argos, 2007. p. 101-122.

SILVA, M. F.; AZEVEDO, M. M. Pensando as escolas dos povos indígenas no Brasil: o movimento dos professores indígenas do Amazonas, Roraima e Acre. In: SILVA L; GRUPIONI, L. D. B. (Org.). A temática indígena na escola: novos subsídios para professores de $1^{\circ}$ e $2^{\circ}$ graus. Brasília: MEC/MARI/UNESCO, 1995.

SILVA, P. B. G. Diversidade Étnico-cultural e Currículo Escolares. Caderno Cedes, São Paulo, n. 32, 1993, p. 25-34.

TOMMASINO, K. A Educação Indígena no Paraná. Revista Mediações, Londrina, v. 8, n. I, p. 71-98, Jan./Jun. 2003.

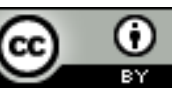

License information: This is an open-access article distributed under the terms of the Creative Commons Attribution License, which permits unrestricted use, distribution, and reproduction in any medium, provided the original work is properly cited.

Article received on July 21, 2017.

Accepted on January 20, 2018. 